\title{
Inflammatory Bowel Disease in The Elderly - Knowledge Gaps and Potential Directions in Research
}

ISSN: 2637-7632

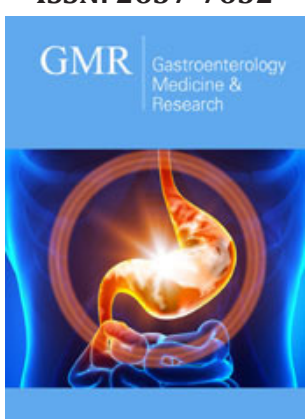

*Corresponding author: Walter Fries, Department of Clinical and Experimental Medicine, Clinical Unit for Chronic Bowel Disorders, Messina, Italy

Submission: 侮 May 30, 2019

Published: 嶆June 12, 2019

Volume 3 - Issue 2

How to cite this article: A. Viola, W. Fries. Inflammatory Bowel Disease in The Elderly -Knowledge Gaps and Potential Directions in Research. Gastro Med Res. 3(2). GMR.000560. 2019.

DOI: 10.31031/GMR.2019.03.000560

Copyright@ Walter Fries,This article is distributed under the terms of the Creative Commons Attribution 4.0 International License, which permits unrestricted use and redistribution provided that the original author and source are credited.

\author{
Anna Viola and Walter Fries* \\ Department of Clinical and Experimental Medicine, Italy
}

\begin{abstract}
Elderly patients with Inflammatory Bowel Disease (IBD) are becoming more frequent in incidence and prevalence. Several topics concerning this particular population have been investigated in the last years but data are still insufficient and current guidelines frequently do not address this problem. The aim of this brief review was to highlight knowledge gaps in this setting of patients. To our opinion, the main gaps in literature concern therapy and prophylaxis of thromboembolism, fracture risk, response to pharmacological therapies, nutrition, faecal incontinence, and post surgical recurrence.
\end{abstract}

Keywords: Elderly; Infections; Surgery; Nutrition; Fracture risk

Abbreviations: IBD: Inflammatory Bowel Disease

Introduction

Elderly subjects with IBD are divided into two distinct populations, one who experience disease onset beyond 60 years of age and the other reaching geriatric age after years or decades of bowel disease. On the former population we do have data on disease extension and behaviour at onset and the use (or suspected underuse) of pharmacological therapies, i.e. immunosuppressive and biological agents, and, finally, surgery [1-7]. Whereas concerning the latter population, much effort has been spent on critical issues such as infections, vaccinations, thromboembolism, osteoporosis, and, lately, biologic therapies but most of these issues are still not included in current clinical guidelines. The scope of this brief review is not to discuss differences in literature on this topic but to highlight knowledge gaps, concerning both populations, i.e. patients with longstanding disease and those with late onset disease.

\section{Discussion}

\section{Infections}

Infections due to opportunistic agents or real pathogens and the relative influence of various immunosuppressive therapies have been extensively studied in all age groups of IBD and were included in current guidelines [8]. Poor knowledge is available on issues like the epidemiology on TBC exposure in elderly patients, adherence to vaccination programs in elderly IBD patients and their response to specific vaccinations.

\section{Thromboembolism}

The risk of thrombosis is well known in elderly individuals [9], especially when affected with IBD [10]. In a very large study on a US hospital discharge database, the risk for thrombosis was greater in hospitalized UC patient compared with CD (OR, Odds ratio, 1.85, 95\% CI 1.702.01) leading to prolonged hospital stays and greater mortality. The older the age the higher was the risk for deep venous thrombosis with a $20 \%$ increase of odds for every additive decade of age (OR 1.20, 95\% CI 1.15-1.25) [11]. Besides this epidemiological knowledge and guidelines on its prevention, no data are available on therapy especially in elderly IBD patients. In a very recent paper, increased needs for hospitalization and blood transfusions have been reported in IBD patients with active disease on anticoagulant therapy [12]. Although the aforementioned paper was not specifically analysed for elderly IBD patients, its importance seems to be predictable since indications for treatment with new oral anticoagulants like the prevention of central nervous events in atrial fibrillation or the treatment and prevention of deep venous thrombosis are increasing with age. 


\section{Osteoporosis}

In the most recent nationwide population based IBD cohort study from Sweden [13] an increased risk for hip fractures was found to be associated with systemic steroid use in elderly IBD patients. At present no data are available if steroids with low bioavailability may reduce this risk in the elderly IBD population. We do not know how many elderly patients do receive an adequate treatment for the prevention of complications of osteoporosis.

\section{Response to pharmacological therapies}

Theoretically, all therapies for adult IBD patients are indicated for elderly IBD patients. Concerning steroids, there is only one report on a better outcome in late onset UC patients after systemic steroid therapy, [14] a finding not confirmed by other investigators [5]. The value of low bioavailability steroids such as budesonide or beclomethasone, are only occasionally reported in elderly IBD patients [7]. Virtually unknown is the efficacy of thiopurines in elderly IBD patients, most studies concentrate on safety issues in this population reporting an increased incidence of non-melanoma skin cancer, lymphomas, and urinary tract cancer when exposed to thiopurines [15-17]. No data were available on methotrexate. Elderly patients were mostly excluded from clinical trials with biologic therapies [18]. Only very recently, real world data on efficacy and safety of anti-TNF and anti-integrin therapies have been published pointing to a lesser persistence in therapy with anti-TNF [19,20].

\section{Nutrition in the elderly}

Little attention has been given to the nutritional support in elderly IBD patients. There is some evidence concerning pancreatic insufficiency found in $18 \%$ of adult IBD patients [21] and this figure may increase with age. The nutritional status impacts greatly the response to biological therapies [22] and surgery outcome [23,24]. Another important issue is the effect of the diet on the composition of microbiome and on the intestinal immune status. Exclusive enteral nutrition is effective in inducing remission in patients with Crohn's disease [25]. Most of evidence comes from paediatric studies with remission rates from $50 \%$ to $80 \%$ in children fed with an exclusive polymer diet for 6-8 weeks. A study by Levine et al showed as a diet therapy with partial enteral nutrition associated with an exclusion diet induced high rates of remission at 8 weeks in paediatric patients and adults with mild to moderate CD 78 and $70 \%$ respectively [26]. No data are available on the elderly IBD population where malnutrition is a common finding,

\section{Faecal incontinence}

Other important factors in determining poor quality of life in IBD patients are represented by a lower rectal compliance and the subsequent faecal incontinence limiting the approach with topical therapies, e.g. enemas [27]. This problem is surely more prominent after rectal surgery including pouch surgery [28]. Most studies have been carried out in younger adult IBD populations, but age seems to be associated with more prominent symptoms [29].

\section{Post-surgical recurrence}

Surgical resection is an important treatment option for Crohn's disease but about 70-90\% of patients show a recurrence within 12 months $[30,31]$. In population studies, the overall rate of clinical recurrence ranges from $28 \%$ to $45 \%$ and from 36 to $61 \%$ at 5 and 10 years respectively [32]. While several studies assessed disease outcome in the elderly patient, there are no data on incidence and risk factors for post-surgical recurrence. Also, data about treatments aimed to reduce recurrence refer to adult populations in which, treatments such as anti-TNF alpha are more frequent and effective.

\section{Conclusion}

In conclusion, with the increasing prevalence of elderly subjects within the IBD population, this population needs more attention than given. Multidisciplinary teams are needed to correctly treat and follow these patients. This short review wanted to list up some issues worthy to get more awareness on the part of the caregivers.

\section{References}

1. Lakatos PL, David G, Pandur T, Erdelyi Z, Mester G, et al. (2011) IBD in the elderly population: results from a population-based study in western hungary, 1977-2008. J Crohns Colitis 5(1): 5-13.

2. Charpentier C, Salleron J, Savoye G, Fumery M, Merle V, et al. (2014) Natural history of elderly-onset inflammatory bowel disease: a population-based cohort study. Gut 63(3): 423-432.

3. Jeuring SF, Heuvel TR, Zeegers MP, Hameeteman WH, Camps MJR, et al. (2016) Epidemiology and long-term outcome of inflammatory bowel disease diagnosed at elderly age-an increasing distinct entity? Inflamm Bowel Dis 22(6): 1425-1434.

4. Mañosa M, Calafat M, Francisco R, García C, Casanova MJ, et al. (2018) Phenotype and natural history of elderly onset inflammatory bowel disease: a multicentre, case-control study. Aliment Pharmacol Ther 47(5): 605-614.

5. Fries W, Viola A, Manetti N, Frankovic I, Pugliese D, et al. (2017) Disease patterns in late-onset ulcerative colitis: results from the IG-IBD "AGED study". Dig Liver Dis 49(1): 17-23.

6. Everhov ÅH, Halfvarson J, Myrelid P, Sachs MC, Nordenvall C, et al. (2018) Incidence and treatment of patients diagnosed with inflammatory bowel diseases at 60 years or older in Sweden. Gastroenterology 154(3): 518528.

7. Viola A, Monterubbianesi R, Scalisi G, Furfaro F, Rea M, et al. (2019) Late-onset Crohn's disease: a comparison of disease behaviour and therapy with younger adult patients - the IG-IBD "AGED" study. Eur J Gastroenterol Hepatol in press.

8. Rahier JF, Magro F, Abreu C, Armuzzi A, Horin SB, et al (2014) Second european evidence-based consensus on the prevention, diagnosis and management of opportunistic infections in inflammatory bowel disease. J Crohns Colitis 8(6): 443-468.

9. Heit JA (2015) Epidemiology of venous thromboembolism. Nat Rev Cardiol 12(8): 464-474.

10. John ES, Katz K, Saxena M, Chokhavatia S, Katz S (2016) Management of inflammatory bowel disease in the elderly. Curr Treat Options Gastroenterol 14(3): 285-304.

11. Nguyen GC, Sam J (2008) Rising prevalence of venous thromboembolism and its impact on mortality among hospitalized inflammatory bowel disease patients. Am J Gastroenterol 103(9): 2272-2280. 
12. Sultan K, Shah D, Bhorania K, Zhou E, Khan S, et al. (2019) Increased transfusion requirements with pharmacologic thromboembolism prophylaxis during inflammatory bowel disease exacerbation. Dig Dis Sci.

13. Ludvigsson JF, Mahl M, Sachs MC, Björk J, Michaelsson K, et al. (2019) Fracture risk in patients with inflammatory bowel disease: a nationwide population-based cohort study from 1964 to 2014. Am J Gastroenterol 114(2): 291-304.

14. Ha CY, Newberry RD, Stone CD, Ciorba MA (2010) Patients with lateadult-onset ulcerative colitis have better outcomes than those with early onset disease. Clin Gastroenterol Hepatol 8(8): 682-687.

15. Biroulet LP, Khosrotehrani K, Carrat F, Bouvier AM, Chevaux JB, et al. (2011) Increased risk for nonmelanoma skin cancers in patients who receive thiopurines for inflammatory bowel disease. Gastroenterology 141(5): 1621-1628.

16. Beaugerie L, Brousse N, Bouvier AM, Colombel JF, Lémann M, et al (2009) Lymphoproliferative disorders in patients receiving thiopurines for inflammatory bowel disease: A prospective observational cohort study. Lancet 374(9701): 1617-1625.

17. Bourrier A, Carrat F, Colombel JF, Bouvier AM, Abitbol V, et al. (2016) Excess risk of urinary tract cancers in patients receiving thiopurines for inflammatory bowel disease: a prospective observational cohort study. Aliment Pharmacol Ther 43(2): 252-261.

18. Baggenstos BR, Hanson BJ, Shaukat A (2013) Treatment of ulcerative colitis in the elderly: a systematic review. Clinical Medicine Insights: Geriatrics 6: 1-26.

19. Lobatón T, Ferrante M, Rutgeerts P, Ballet V, Assche G, et al. (2015) Efficacy and safety of anti-TNF therapy in elderly patients with inflammatory bowel disease. Aliment Pharmacol Ther 42(4): 441-451.

20. Adar T, Faleck D, Sasidharan S, Cushing K, Borren NZ, et al. (2019) Comparative safety and effectiveness of tumor necrosis factor $\alpha$ antagonists and vedolizumab in elderly IBD patients: A multicentre study. Aliment Pharmacol Ther 49(7): 873-879.

21. Maconi G, Dominici R, Molteni M, Ardizzone S, Bosani M, et al. (2008) Prevalence of pancreatic insufficiency in inflammatory bowel diseases. Assessment by fecal elastase-1. Dig Dis Sci 53(1): 262-270.
22. Dotan I, Ron Y, Yanai H, Becker S, Fishman S, et al. (2014) Patient factors that increase infliximab clearance and shorten half-life in inflammatory bowel disease: a population pharmacokinetic study. Inflamm Bowel Dis 20(12): 2247-2259.

23. Sanromán AL (2019) Steroids and postoperative complications in IBD. Curr Drug Targets.

24. Ryan E, Nicholas D, Creavin B, Kelly ME, Walsh T, et al. (2019) Sarcopenia and inflammatory bowel disease: a systematic review. Inflamm Bowel Dis 25(1): 67-73.

25. Grover Z, Muir R, Lewindon P (2014) Exclusive enteral nutrition induces early clinical, mucosal and transmural remission in paediatric Crohn's disease. J Gastroenterol 49(4): 683-645.

26. Levine A, Wine E (2013) Effects of enteral nutrition on Crohn's disease: clues to the impact of diet on disease pathogenesis. Inflamm Bowel Dis 19(6):1322-1329

27. Limdi JK, Vasant DH (2016) Anorectal dysfunction in distal ulcerative colitis: challenges and opportunities for topical therapy. J Crohns Colitis 10(4): 503 .

28. Song EM, Lee HS, Park SH, Kim GU, Seo M, et al. (2018) Clinical characteristics and long-term prognosis of elderly onset ulcerative colitis. J Gastroenterol Hepatol 33(1): 172-179.

29. Norton C, Dibley LB, Bassett P (2013) Faecal incontinence in inflammatory bowel disease: associations and effect on quality of life. J Crohns Colitis 7(8): e302-e311.

30. Buisson A, Chevaux JB, Allen PB, Bommelaer G, Biroulet LP (2012) Review article: the natural history of postoperative Crohn's disease recurrence. Aliment Pharmacol Ther 35(6): 625-633.

31. Olaison G, Smedh K, Sjodahl R (1992) Natural course of Crohn's disease after ileocolic resection: endoscopically visualised ileal ulcers preceding symptoms. Gut 33(3): 331-335.

32. Rutgeerts P, Geboes K, Vantrappen G, Beyls J, Kerremans R, et al. (1990) Predictability of the postoperative course of Crohn's disease. Gastroenterology 99(4): 956-963. 